\title{
Vav1: A Key Player in Agonist-Induced Differentiation of Promyelocytes from Acute Myeloid Leukemia (APL)
}

\author{
Valeria Bertagnolo, Federica Brugnoli and Silvano Capitani \\ University of Ferrara, Section of Human Anatomy, \\ Department of Morphology and Embryology, \\ Italy
}

\section{Introduction}

Acute promyelocytic leukemia (APL) is the M3 subtype of acute myeloid leukemia (AML), characterized by aberrant hyperproliferation of progenitors originally committed to terminal differentiation into granulocytes but blocked at the promyelocytic stage. Although clinical studies have introduced treatments employing arsenic trioxide, anthracyclines and anti-CD33 monoclonal antibodies, all-trans retinoic acid (ATRA)-based therapy represents, until today, the standard cure of APL patients (Lo-Coco \& Ammatuna, 2006; Tallman, 2007). ATRA treatment of APL constitutes, at present, the only example of successful differentiation therapy of a human cancer, in which tumor cells are induced to complete their maturation to neutrophils. Studies on both APL blasts and APL-derived cell lines have elucidated that ATRA acts throughout a complex network that includes the degradation of the PML/RAR $\alpha$ fusion protein and the activation of RAR $\alpha$-mediated gene transcription (Breitman et al., 1980; Lanotte et al., 1991; Yang et al., 2003). In addition, it has been reported that ATRA- and phorbol 12-myristate 13-acetate (PMA)-mediated differentiation of human myeloid leukemia cell lines results in changes of their sensitivity to chemotherapeutic drugs, suggesting that advantages in the cure of APL and other malignancies could be obtained by combining differentiating agents and conventional anticancer drugs (Jasek et al., 2008; Kogan, 2009; Nasr et al., 2008).

Even if the mechanism by which ATRA interacts with its receptor located on specific DNA sequences is well known, the events mediated by the ATRA target genes, able to elicit the integrated signaling networks that promote maturation of tumoral promyelocytes, have not been fully clarified and are currently under study to also identify specific molecular targets for new therapies of APL.

One of the proteins up-regulated by ATRA in APL-derived cells and that resulted chiefly involved in the maturation program of tumoral promyelocytes is Vav1, the sole member of the Vav family of proteins physiologically expressed only in haematopoietic cells, where it works as an important signal transducer in immune response (Katzav, 2009; Tybulewicz, 2005). Relevant insights into the function of Vav1 in hematopoietic cells have been provided by studies with knockout mice, demonstrating that the targeted down-modulation of Vav1 compromises maturation of both lymphoid and myeloid cells (Zhang et al., 1994). In 
particular, a severe impairment of IL-2 production and calcium mobilization in response to external stimuli has been found in T and B cells (Fujikawa et al., 2003; Haubert \& Weckbecker, 2010) and the defective motility observed in the Vav1/- neutrophils, concomitant with the decrease in migration, has been demonstrated to reduce the capacity for an innate immune response (Phillipson et al., 2009). Vav1 has a critical role also in regulating the acquisition by macrophages of maturation-related competence, as demonstrated by the smaller adhesive area, the reduced motility and the lower migration speed of macrophages from Vav1-deficient mice (Hall et al., 2006; Wells et al., 2005). More recently, Vav1 activity has been demonstrated to be required specifically for SDF1adependent perivascular homing and subsequent engraftment of hematopoietic stem cells (Sanchez-Aguilera et al., 2011). In both lymphoid and myeloid cells, Vav1 is involved in the dynamic regulation of the filamentous actin cytoskeleton, critical to numerous physical cellular processes, including adhesion, migration and phagocytosis (Cougoule et al., 2006; Stricker et al., 2010).

Vav1 contains an array of structural motifs that enable it to play a role in several distinct cell functions, like cytoskeletal reorganization and regulation of gene expression during proliferation, maturation, and apoptosis of hematopoietic cells (Clevenger et al., 1995; Fischer et al., 1998; Kong et al., 1998). The Vav1 domains include a DH region which exhibits a GDP/GTP exchange activity for the RhoA, Rac1 and CDC42 small GTPases, a PH domain interacting with phosphoinositides, two $\mathrm{SH} 3$ domains and one $\mathrm{SH} 2$ domain mediating protein-protein interactions, a $\mathrm{CH}$ domain that functions as an actin-binding motif and an AC region that contains 3 regulatory tyrosines. Vav1 also possesses 2 putative nuclear localization signals, indicative for a role of the protein also inside the nuclear compartment (Bustelo, 2001).

In both myeloid and lymphoid cells, the best known function of Vav proteins is the guanosine exchange factor (GEF) for small $G$ proteins which is modulated, at variance with the other exchange factors for Rho/Rac in humans, by phosphorylation on tyrosine residues (Bustelo, 2002). However, some functions of Vav1 in hematopoietic cells are independent of its GEF activity and are attributed to its ability to interact with a number of signalling molecules, in both cytoplasm and nucleus. In particular, inside the nuclear compartment Vav1 seems to play its most intriguing role as part of transcriptionally active complexes (Houlard et al., 2002) and by interacting with components of the DNA-dependent protein kinase complex as well as with hnRNP proteins (Romero et al., 1996, 1998).

In addition to the role played in the acquisition of a mature phenotype by normal hematopoietic cells, Vav1 has been found to promote the agonist-induced completion of the differentiation program of tumoral myeloid precursors. In cell lines derived from APL patiens treated with differentiating agents Vav1 plays indeed multiple roles aimed to regulate different aspects of maturation along the neutrophilic and the monocytic/macrophagic lineages. Since Vav1 may be recruited by various differentiating agents and plays a central role in the completion of the differentiation program of leukemic promyelocytes along diverse hematopoietic lineages, it might be considered a common target for developing new therapeutic strategies for the different subtypes of myeloid leukemias.

\section{Vav1 and netrophil-like phenotypical maturation}

Promyelocytes derived from APL, which are blocked at different steps of their neutrophil differentiation, contain levels of Vav1 variably lower than those found in mature 
neutrophils. Treatments with differentiating doses of ATRA induce a significant increase of Vav1 expression in primary blasts obtained from the bone marrow of APL patients as well as in the APL-derived cell lines HL-60 and NB4. A similar increase of Vav1 is observed when normal CD34+ hematopoietic progenitors are treated with a cytokine cocktail promoting granulocytic differentiation, clearly indicating that an adequate expression of Vav1 has to be achieved along with neutrophil maturation of both normal precursors and poorly differentiated neoplastic cells (Bertagnolo et al., 2005). These evidence, obtained in a variety of normal and neoplastic cells under different experimental conditions, ascribe to Vav1 the potential role of a ubiquitous key player in the path leading myeloid precursors to acquire the mature phenotype of differentiated neutrophils.

The issue of whether the increase of Vav1 observed in differentiation of tumoral promyelocytes is merely designed to the function of the protein in mature cells or, more intriguingly, it is functionally relevant to the maturation mechanism, has been addressed by studies in which the expression of Vav1 was forcedly modulated. The experiments have been performed in ATRA treated HL-60 and NB4 cells, which are blocked at different levels of granulocytic differentiation, and thus constitute models well suited to better understand the role of Vav1 in the maturation process. As a consequence of Vav1 over-expression during ATRA treatment of both cell lines, the expression of the myeloid surface marker CD11b increases, indicating that Vav1 supports the role of ATRA in regulating the maturation process. On the other hand, the sole over-expression of Vav1 is capable to significantly induce the expression of CD11b only in HL-60 cells, that, compared to NB4 cells, are blocked to a less differentiated stage (Bertagnolo et al., 2005). This suggests the existence of a direct and ATRA-independent role of Vav1 in regulating the expression of $\mathrm{CD} 11 \mathrm{~b}$, at least in cells that are blocked at early stages of the neutrophilic maturation.

Neutrophils radically change in shape during development and functional life (Sanchez \& Wangh, 1999). Accordingly, profound rearrangements of the cell morphology take place throughout differentiation of myeloid precursors along the granulocytic lineage, and the nucleus is the cell compartment that undergoes the biggest architectural changes by a mechanism still largely unknown. Modifications of the nuclear shape constitute one of the markers of neutrophil maturation of tumoral promyelocytes and are particularly evident after treatment with ATRA of HL-60 cells, according to the notion that this cell type is blocked at an early stage of maturation. On the other hand, the sole over-expression of Vav1 is unable to induce nuclear modifications in both HL-60 and NB4 cells, indicating that other ATRA-induced events are required to regulate the maturation-related rearrangements of cell morphology (Bertagnolo et al, 2005).

The use of siRNAs specific for Vav1 unequivocally demonstrates that Vav1 is not dispensable for the progression of tumoral promyelocytes along the granulocytic lineage. In fact, the down-modulation of Vav1 expression during ATRA treatment of both HL-60 and NB4 cells counteracts the agonist-induced increase of CD11b expression and prevents the maturation-related modifications of cell/nucleus morphology, definitely assigning to Vav1 a crucial role in regulating phenotypical maturation of APL-derived cells (Bertagnolo et al, 2005, 2008).

\subsection{Tyrosine phosphorylation of Vav1}

In parallel with the increase of Vav1 expression, ATRA treatment of HL-60 and NB4 cells also induces Vav1 tyrosine phosphorylation. Since, in the whole cell, the rise of the 
phosphosphorylation level is almost proportional to the increase in total Vav1 amount, ATRA seems to ensure to differentiating cells the achievement of an adequate amount of tyrosine phosphorylated Vav1, according with the functions of Vav1 in mature neutrophils. On the other hand, the accumulation of tyrosine-phosphorylated Vav1 inside the nuclear compartment seems to be a distinctive feature of the differentiation process induced by ATRA in APL-derived cells (Bertagnolo et al., 2005). In fact, a progressive increase of tyrosine phosphorylated Vav1 inside the nucleus accompanies the agonist-induced maturation (Bertagnolo et al., 1998), indicative of a specific role of tyrosine phosphorylated Vav1 inside the nuclear compartment. The tyrosine phosphorylation level of nuclear Vav1 reaches a maximum in ATRA-treated NB4 cells, which constitute the cell model with the most advanced level of neutrophil maturation among APL-derived precursors (Bertagnolo et al., 2005), clearly correlating tyrosine phosphorylated Vav1 with the maturation-related events that occur inside the nuclear compartment and opening the question of which kinase/s is/are involved in this process.

In both myeloid and lymphoid cells, Vav1 is phosphorylated in tyrosine/s by receptors with intrinsic tyrosine kinase activity or by membrane and/or cytoplasmic tyrosine kinases of the Syk/Zap70, Src and Jak families (Bustelo, 2002). More recently, also the c-Abl kinase has been reported to be specifically involved in regulating the activity of Vav1 in integrinmediated neutrophil adhesion (Cui et al., 2009). Recruitment and phosphorylation of Vav1 depend on its ability to interact with a number of signalling proteins by means of its various domains. In particular, the interaction between the SH2 domain of Vav1 and phosphorylated proteins is thought to serve for recruitment of activated kinases, which in turn can phosphorylate Vav1 (Bustelo, 2002). The Syk/ZAP-70 family of tyrosine kinases constitutes an example of proteins that contain two SH2 domains, a tandem sequence that might confer high specificity in tyrosine kinase- mediated signalling. In addition, both ZAP70 and Syk contain a consensus binding sequence for the Vav1 SH2 domain that seems to be critical for antigen receptor-mediated signal transduction (Ottinger et al., 1998).

Experiments performed with HL-60 cells have demonstrated the association of tyrosine phosphorylated Syk with the Vav1-SH2 domain, in both whole cell and nuclear compartment, as a consequence of ATRA treatment (Bertagnolo et al., 2001). These data are in agreement with the notion that activation of Syk occurs in differentiating HL-60 cells (Qin \& Yamamura, 1997) and mature neutrophils, in which it regulates migration (Schymeinsky et al., 2006) and the formation of lamellipodia during phagocytosis (Shi et al., 2006). While in whole HL-60 cells the Vav1/Syk association takes place regardless of their phosphorylation level and of ATRA treatment, the formation of Vav1/Syk complexes inside the nuclear compartment strongly increases during the differentiation process, suggesting a specific role for this tyrosine kinase in the nucleus. The role of Syk in phosphorylating Vav1 has been demonstrated by means of in vitro assays (Bertagnolo et al., 2001) and confirmed by the use of a pharmacological model of Syk inhibition, in which both HL-60 and NB4 cells were treated with Piceatannol (Bertagnolo et al., 2001, 2008), a tyrosine kinase inhibitor with a reported selectivity for Syk (Law et al, 1999; Seow et al., 2002).

The Syk-dependent tyrosine phosphorylation of Vav1 during the ATRA-induced phenotypical differentiation is not relevant for the expression of the surface marker CD11b, as indicated by the use of Piceatannol in both HL-60 and NB4 cells, but seems to play a crucial role in regulating the reorganization of cell architecture. In fact, when Piceatannol is administered in combination with ATRA, the modifications of nuclear morphology typical of granulocytic differentiation are almost completely abrogated, similarly to what observed when the 
expression of Vav1 is down-modulated during the differentiation treatment (Bertagnolo et al., 2008). However, since Piceatannol fails to abrogate completely the ATRA-induced tyrosine phosphorylation of Vav1 in both HL-60 and NB4 cells (Bertagnolo et al., 2008), other kinase/s, in addition to Syk, are probably recruited by ATRA in these cell models.

The results from these inhibition studies support the hypothesized action model that requires tyrosine phosphorylated Vav1 in maturation of tumoral myeloid precursors. Nevertheless, the issue needs further investigations, in order to identify the kinase/s involved. In fact, by extending the analysis to other tyrosine kinase inhibitors, it has been found that PP1 and AG490, inhibitors of Src and Jak tyrosine kinase families, respectively, did not affect to any significant extent the tyrosine phosphorylation of Vav1 (Bertagnolo et al., 2004), leaving open the question of which other tyrosine kinases, in addition to Syk, phosphorylate Vav1 during maturation of tumoral promyelocytes.

\subsubsection{Participation to protein complexes with signaling molecules}

In addition to the obvious interaction with tyrosine kinases, the optimal phosphorylation of Vav1 seems to require the association with adaptor molecules that facilitate the spatial proximity between Vav1 and the upstream kinases. These associations also depend on the tyrosine phosphorylation of the involved proteins and often require the engagement of either the $\mathrm{SH} 3$ or the SH2 domains of Vav1 as interacting motifs (Bustelo, 2002). In this context, SLP76 , an adaptor protein predominantly expressed in T cells and myeloid cells and which is a substrate for ZAP-70 and Syk tyrosine kinases, has been reported to associate, via tyrosinephosphorylated residues in its NH2-terminal domain, with the SH2 domain of Vav1 after ligation of the T-cell antigen receptor (Tuosto et al., 1996; Pauker \& Barda-Saad,, 2011). SLP-76 was also described as an important adaptor molecule that is regulated by Syk in C-reactive protein-stimulated platelets (Gross et. al, 1999) and that plays a critical role in FcRI-mediated activation of mast cells in vivo and in vitro (Pivniouk et al., 1999).

Some of the Vav1-interacting molecules play a role in down modulation of Vav1 signals. A potential negative regulator of Vav1 is Cbl, which down-modulates Syk/ZAP-70 and other protein tyrosine kinases (Lupher et al., 1999). Cbl associates with Vav1 upon T-cell receptor stimulation of primary murine lymphocytes and Jurkat $\mathrm{T}$ cells. This interaction appears to require the whole $\mathrm{SH} 3-\mathrm{SH} 2-\mathrm{SH} 3 \mathrm{COOH}$-terminal domain of Vav1 and a proline-rich sequence of $\mathrm{Cbl}$ and seems to inhibit the Vav1-dependent signal transduction (Bustelo et al., 1997). Very recently, Chiang \& Hodes (2011) have demonstrated a role of Cbl in repressing signaling events that can mediate thymic differentiation in the absence of Vav1, since Cbl inactivation rescued defective T cell development in Vav1-/- mice.

The molecules involved in the recruitment and phosphorylation of Vav1 during the ATRAdependent granulocytic differentiation of tumoral promyelocytes were investigated in HL60 cells by using GST-fusion NH2-terminal and COOH-terminal Vav1-SH3 and GST-fusion Vav1-SH3-SH2-SH3 proteins. One of the proteins interacting with Vav1 in HL-60 cells is the adaptor molecule $\mathrm{Cbl}$, present only in the cytoplasm and strongly phosphorylated in response to ATRA treatment. The Vav1/Cbl interaction in HL-60 cells occurs also in control conditions and requires the entire SH3-SH2-SH3 domain of Vav1 (Bertagnolo et al., 2001). The adaptor protein SLP-76 has been also identified as a phosphorylated protein interacting with the SH3-SH2-SH3 fragment of Vav1 in both cells and nuclei of HL-60 after ATRA treatment. Similarly to Cbl, SLP-76 associates with Vav1 also in control conditions, without quantitative changes due to the differentiation process. Vav1-associated SLP-76 was more 
abundant in nuclei than in whole cell lysates, indicating a preferential association into the nucleus of these two molecules, in contrast with an exclusive cytoplasmic distribution of Vav1/Cbl complexes (Bertagnolo et al., 2001).

The interaction of Vav1 with Cbl and SLP-76 in HL-60 cells may be correlated to the transmembrane signaling mediated by CD38, an early biomarker of ATRA-induced differentiation in the HL-60 cell line, in which it may play a causal role in myeloid differentiation (Lamkin et al., 2006). A correlation between Vav1 and CD38-activated signaling has been recently demonstrated by experiments in which the expression of a cytosolic deletion mutant of CD38 caused failure to up-regulate ATRA-induced proteins such as CD11b, Vav1 and Fgr, this latter able to phosphorylate Vav1 after ATRA treatment of HL-60 cells (Congleton et al., 2011).

Exclusive of the ATRA treatment of HL-60 seems to be the compartmentalized association between Vav1 and interacting proteins during ATRA treatment, since Cbl/Vav1 complexes are located in the cytoplasm while SLP-76/Vav1 complexes reside in the inner nuclear compartment. This suggests that Vav1 is recruited by one or more signal transduction cascades, starting from cell membrane and directed to the nucleus and involving the two adaptor proteins $\mathrm{Cbl}$ and SLP-76, which may then discretely regulate the amount of Vav1 in the cytoplasmic and nuclear compartments (Fig. 1).

The Vav1-associated protein complexes identified in HL-60 cells also contain the tyrosine kinase Syk. In particular, Vav1/Cbl/Syk complexes have been found in cytoplasm whereas Vav1/SLP-76/Syk complexes have been demonstrated inside the nuclear compartment. These associations are present in control conditions and result strongly increased after ATRA treatment (Bertagnolo et al., 2001). This suggests that, during the maturation of APLderived myeloid precursors, a sequence of signals originated from membrane receptors and directed to the nuclear compartment is ended to regulate the amount of tyrosine phosphorylated Vav1 inside the nucleus (Fig. 1) and that this pathway may involve the negative regulation of $\mathrm{Cbl}$ on Vav1 activity.

In both cells and nuclei of HL-60 cells, other signalling molecules associate with Vav1 as a consequence of ATRA treatment. They include the $\gamma 1$ isoform of PI-PLC and the p85 regulatory subunit of PI3K. In particular, ATRA treatment increases the binding of tyrosinephosphorylated Vav1 to both N-terminal and C-terminal SH2 domains of p85 (Bertagnolo et al., 1998). Since Vav1 is the only member of the Vav1/PLC- $\gamma 1 /$ PI3K complex to possess a nuclear localization sequence (Bustelo, 2001), it is conceivable that Vav1 is directly involved in regulating the amount of PLC- $\gamma 1$ and PI3K inside the nuclear compartment.

\subsubsection{Phosphorylation of Vav1 on Tyr745}

Vav1 contains 31 tyrosine residues whose phosphorylation was originally investigated almost exclusively in relation to the function of Vav1 as a GEF. A crucial role in this context seems to be played by Tyr174 in both lymphoid and myeloid cells, even if other mechanisms have emerged in the last few years as regulators of Vav1 GEF activity, and recent data suggest that Tyr174 is coversely involved in roles of Vav1 not mediated by GEF activity (Katzav, 2009). In addition to Tyr174, other conserved residues, Tyr142 and Tyr160, have been described to be phosphorylated in activated Vav1. It has also been suggested that phosphorylation of the tyrosines located inside the acidic region of Vav1 may allow Tyr142, Tyr160, and Tyr174 to become docking sites for kinases, which can then phosphorylate additional tyrosine residues in Vav proteins (Miletic et al., 2006; Yu et al., 2010). Recently, 
several of the tyrosine residues at the carboxyl terminus of Vav1 have been shown to be phosphorylated in cancer cells, raising the possibility that also these tyrosine residues play an important role in Vav1 function (Lazer et al., 2010).

The residue Tyr174, phosphorylated by members of Syk/Zap70 and Src tyrosine kinase families, plays a central role in regulating GEF activity of Vav1 in mature neutrophils, including $\beta 2$ integrin-mediated neutrophil migration in vitro and neutrophil recruitment during the inflammatory response in vivo (Schymeinsky et al., 2006). In APL-derived cells, ATRA induces the phosphorylation of Tyr174 in NB4 but not in HL-60 cells and independently of the activity of Syk (Bertagnolo et al., 2011). Both cytofluorimetrical analysis of CD11b expression and migration assays on NB4 cells over-expressing the Tyr174Phemutated Vav1 have ruled out any relevant role for this tyrosine residue in supporting the activity of ATRA in this cell line (Bertagnolo et al., 2010). Since phosphorylation of Tyr174 in neutrophils has been mainly associated to the GEF activity of Vav1 in mature cells, these findings suggest that the ATRA-induced phosphorylation of Tyr174 occurs in parallel with differentiation and may constitute a marker of the acquisition of a mature phenotype. This hypothesis is confirmed by the failure of ATRA in inducing the phosphorylation of Tyr174 in HL-60 cells, that reach indeed only a partially differentiatiated phenotype (Bertagnolo et al., 2011).

Since the phosphorylation of Vav1 on the Tyr174 residue seems unrelated to the path by which tyrosine phosphorylated Vav1 affects the ATRA-induced maturation of APL-derived cells, proteomic studies have been undertaken to identify other tyrosine residues phosphorylated after ATRA treament in both HL-60 and NB4 cells. Mass spectra analysis performed on Vav1 immunoprecipitated from NB4 whole cells identified Tyr745 as an ATRA-induced phosphorylated residue, within a highly conserved Vav1 sequence. The analysis of maturation-related features in differentiating NB4 cells over-expressing the Tyr745Phe-mutated form of Vav1 have clearly shown that phosphorylation of this tyrosine residue is crucial in regulating CD11b expression as well as in promoting the acquisition of migratory capabilities (Bertagnolo et al., 2010). Even if Tyr745 has never been correlated with the known roles of Vav1, multiple sequence alignment analysis of proteins from different species indicates that this is a highly conserved aminoacid, likely involved in physiological roles of Vav1.

Inhibition studies have ruled out the role of Syk in phosphorylating Tyr745 as a consequence of ATRA treatment and, at present, no data are available about the involved tyrosine kinase. This is in part due to the fact that analysis performed with softwares designed to predict cell signaling interactions using short sequence motifs failed to recognize the Tyr745 of Vav1 as a putative phosphorylation site by the known tyrosine kinases. However, some tyrosine residues of Vav1 are not surface exposed and/or may be involved in intramolecular interactions, thereby precluding their tyrosine phosphorylation and impairing their recognition by the data base analysis. Since Tyr745 is located inside a short helix on the SH2 domain of Vav1, its phosphorylation could be an event secondary to phosphorylation of other tyrosine residues, which may induce conformational changes of Vav1 allowing Tyr745 to become accessible to a specific tyrosine kinase.

\subsubsection{GEF activity}

The best known function of tyrosine phosphorylated Vav1 is a catalytic role as a GEF towards the Rho family of GTPases, in which Tyr174 is crucial. Tyr174 lies within an a-helix 
and binds directly with the GTPase interaction pocket of the DH domain, blocking access to substrate and inhibiting Vav1 GEF activity. Phosphorylation releases Tyr174 from the binding pocket, relieving the auto-inhibition (Bustelo et al., 2001). The activity of the DH domain is also regulated by the $\mathrm{CH}$ domain, as deletion of this domain results in constitutively active GEF activity. It has been suggested that the Vav1 $\mathrm{CH}$ domain can bind to the $\mathrm{C} 1$ region, occluding the $\mathrm{DH}$ domain and blocking access to GTPases. $\mathrm{CH}-\mathrm{C} 1$ interaction apparently stabilizes the inhibitory Tyr174-DH interaction. In addition, the PH domain regulates Vav1 catalytic activity by interaction with two inositol lipids: phosphatidylinositol 4, 5- bisphosphate ( $\left.\mathrm{PIP}_{2}\right)$ and phosphatidylinositol 3, 4, 5-trisphosphate $\left(\mathrm{PIP}_{3}\right)$. Whereas the binding of $\mathrm{PIP}_{3}$ moderately enhances the in vitro GEF activity of Vav1, binding to $\mathrm{PIP}_{2}$ has an inhibitory effect. Consistent with this model, Vav1 carrying a single mutation in its $\mathrm{PH}$ domain is constitutively active and induces cytoskeleton rearrangements as a consequence of Rac activation. Deletions of $\mathrm{C} 1$ domain or mutations that disrupt its structural integrity inhibit Vav1 GEF activity. High resolution X-ray structure of DH-PH-C1 domains suggests that $\mathrm{PH}$ and $\mathrm{C} 1$ domains contribute to GEF activity by stabilizing the $\mathrm{DH}$ domain structure and not through direct contacts with GTPases (Bustelo, 2002).

GEF activity of Vav1 has long been regarded as the key for transferring the signal from activated receptors to the cytoskeleton. Among the molecules constituting the cytoskeleton architecture, actin seems to be a preferred target of the Vav1-dependent GEF activity. Several partners are involved in the pathway by which Vav1 affects actin cytoskeleton. It has been reported that Vav1 is a preferential exchange factor for Rac1, which in turn may activate phosphatidylinositol-4-phosphate (PIP) 5-kinase which phosphorylates PIP to PIP 2 . $\mathrm{PIP}_{2}$ may function as an activator of actin-binding proteins, like talin and vinculin, that attach the cytoskeleton to the cell membrane. Another potential target for the GEF activity of Vav1, Cdc42, may activate the WASP protein, a key mediator of actin polymerization (Hornstein et al., 2004). Finally, Vav1-activated small G proteins play an essential role in regulating actin cytoskeleton dynamics by also interacting with the p21-activated serinethreonine kinase (PAK) family of actin-regulatory enzymes (Daniels \& Bokoch, 1999).

In both lymphoid and myeloid cells, like other proteins with a GEF activity, Vav1 mediates a number of cytoskeletal-associated cellular processes, being an essential part of the molecular link connecting activated receptors to the actin cytoskeleton. A consistent number of studies (reviewed in Hornstein et al., 2004) have reported the role of Vav1 in the formation of immunological synapse and in phagocytosis of $\mathrm{T}$ cells. In non adherent neutrophils, stimulation of chemoattractant receptors induces a complex sequence of events: actin reorganization, shape changes, development of polarity and reversible adhesion, all culminating in chemotaxis. The complex signaling mechanisms that regulate neutrophil migration are well studied, and Vav1 appears to be a major point of the inhibitory crosstalk between adhesion receptors and cytokine receptors (Gakidis et al., 2004). In particular, the activity of Vav1 as GEF for Rac2 is inhibited in adherent cells, as a possible consequence of the activation by adhesion of one or more tyrosine phosphatases responsible of dephosphorylating Vav1. On the other hand, experiments performed with Vav1-/- mice have demonstrated that motility and mobilization into peripheral blood induced in neutrophils by FMLP are significantly reduced, as well as the generation of filamentous actin (Kim et al., 2003). Studies performed in a rat model have demonstrated that the MCSF-induced chemotaxis of bone marrow macrophages is initiated by the 3phosphoinositide-dependent GEF activity of Vav1 on Rac (Vedham et al., 2005). 
In APL-derived HL-60 cells, ATRA treatment induces an increase of total GEF activity, not attributable to Vav1, as deduced by in vitro assays on Ras/Rac small G proteins performed on Vav1 immunoprecipitated from both whole cells and isolated nuclei (Bertagnolo et al., 2001). This implies that, in this cell model, the Syk-dependent tyrosine phosphorylation of Vav1 is not ended to regulate its GEF activity and that alternative pathways have to be considered to explain the mechanism by which Vav1 affects the organization of cytoskeleton and nucleoskeleton during maturation of tumoral promyelocytes.

\subsection{GEF-independent activity of phosphorylated Vav1 \\ 2.2.1 Regulation of actin cytoskeleton}

In addition to act as a GEF, Vav1 may mediate actin reorganization through other, GEFindependent mechanisms. The presence in its structure of a number of tyrosines and domains potentially involved in protein-protein interactions suggests for Vav1 a role in actin polymerization as an adapter protein that links signaling and cytoskeletal molecules. In T cells, Vav1 binds constitutively Talin and Vinculin, anchoring the actin cytoskeleton to the plasma membrane, and the cytoskeletal protein Zyxin (Hornstein et al., 2004). In the same cell model, a direct link between Vav1 and dynamin 2 (Dyn2), a component of the cytoskeletal regulators, has also been demonstrated (Gomez et al., 2005).

A mechanism by means of which tyrosine-phosphorylated Vav1 regulates cytoskeleton of ATRA-treated tumoral promyelocytes, identified in HL-60 cells, implies the interaction of Vav1 with the p85 regulatory subunit of PI3K. Studies aimed to establish the functional meaning of this interaction have demonstrated that, in maturating myeloid precursors, PI3K activity closely depends on its association with tyrosine phosphorylated Vav1 and that when Vav1/PI3K interaction and/or PI3K activity are abrogated, the phenotypic differentiation of ATRA-treated HL-60 is compromised (Bertagnolo et al., 1999, 2004). These evidence assign to Vav1/PI3K interaction a prominent function in the regulation of cytoskeleton alternative to the described role of 3-phosphoinositides on GEF activity of Vav1 (Han et al., 1998).

Also actin participates in the ATRA-induced protein complexes containing Vav1 and PI3K in HL-60 cells. Remarkably, when the association between Vav1 and PI3K is inhibited, the formation of PI3K/actin complexes is reduced, suggesting that the interaction of PI3K with Vav1 is essential for its association with actin (Bertagnolo et al., 2004). Since the recovery of 3-phosphoinositides is strongly reduced when the Vav1-dependent PI3K/actin interaction is abrogated, it can be concluded that Vav1 regulates the physical contact of PI3K with their cytoskeleton-associated substrates. These observations suggest that in addition to playing a regulatory role in Vav1 activation, PI3K activity may itself be regulated by Vav1.

PI3K is likely to play essential roles in granulocytic differentiation of tumoral myeloid precursors, considering that both down-modulation of its expression and pharmacological inhibition of its activity during ATRA treatment significantly reduce the tendency of HL-60 cells to acquire the differentiated phenotype (Bertagnolo et al., 1999). The response to ATRA and the downstream effects of PI3K observed during the induced differentiation support the notion that PI3K is recruited in the path controling cytoskeleton in mature granulocytes. In fact, PI3K is activated in response to chemotactic factors in murine and human neutrophils (Cicchetti et al., 2002; Niggli \& Keller, 1997; Stephens et al., 2002) in which newly produced $\mathrm{PIP}_{3}$ is involved in determining the localization and possibly the crosslinking/stabilization of actin filaments (Chen et al., 2003; Hannigan et al., 2002; Wang et al., 2002). In vitro experiments 
have demonstrated that PI3K may affect actin-related modifications of cytoskeleton also by directly affecting PAK kinase activity (Menard \& Mattingly, 2004). PI3K has a more general influence on cytoskeleton by determining the amount of the inositol-containing lipids, that have emerged as major players in regulating actin assembly at several levels and with different mechanisms, including the direct interaction with cytoskeletal proteins, such as vinculin and gelsolin (Janmey et al., 1999, Takenawa \& Itoh, 2001).

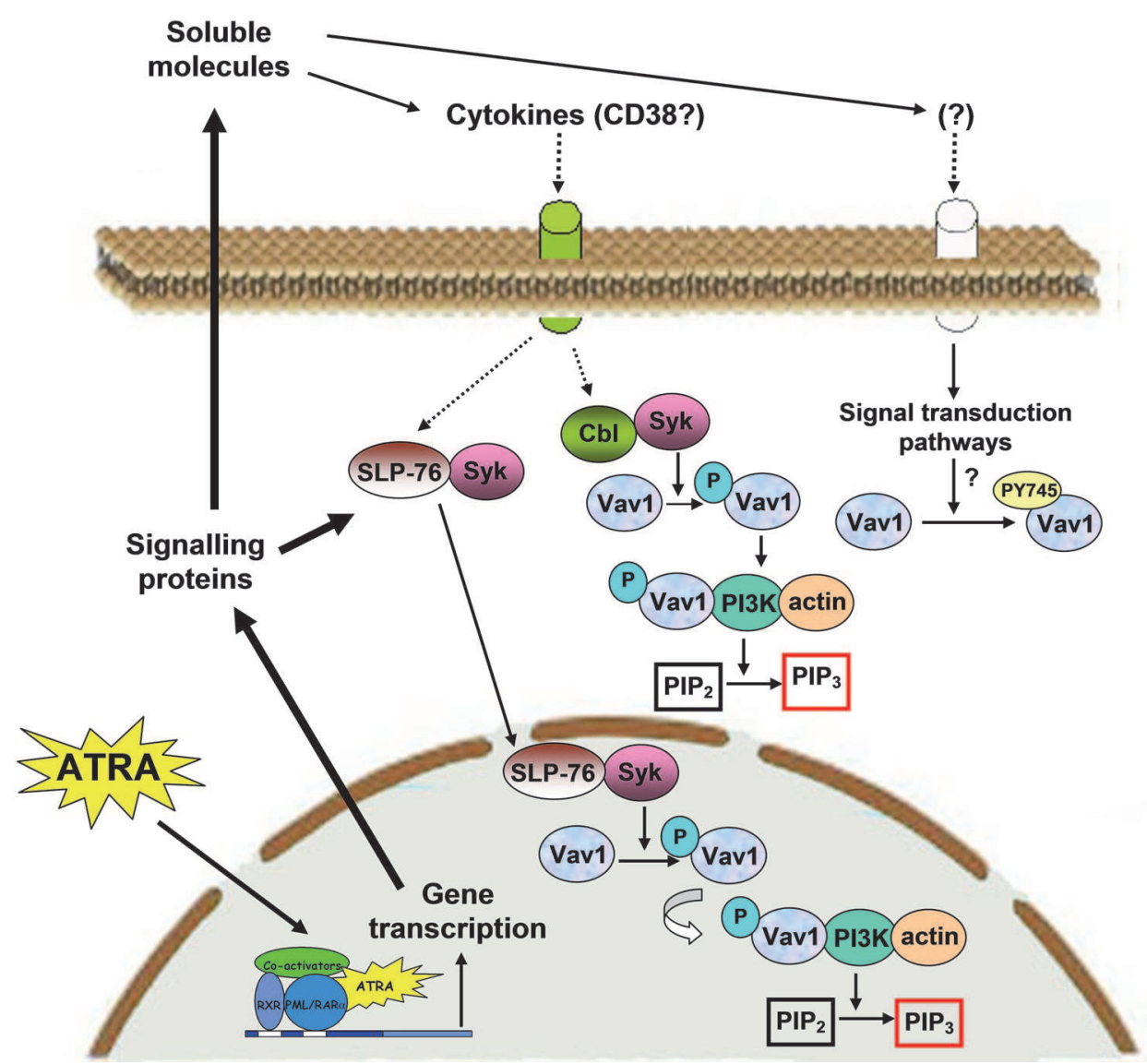

Fig. 1. Schematic representation of the recruitment and phosphorylation of Vav1 in ATRAtreated promyelocytes.

Since, in ATRA-treated promyelocytes, both PI3K activity and the modifications of the nucleus architecture depend on the formation of Vav1/PI3K complexes, Vav1 may be important for targeting PI3K to its nuclear substrates. The association of Vav1 with other lipid modifying enzymes, including specific PI-PLC isoforms (Bertagnolo et al., 1998;), suggests a more general role of Vav1 in determining the composition of the actin-associated phosphoinositide pool and, ultimately, in regulating actin polymerization in differentiating HL-60 cells. 


\subsubsection{Regulation of gene expression}

Microarray analysis performed on APL-derived cell lines has identified several genes whose expression is modified by ATRA treatment, including genes for a number of cytokines, in turn involved in the differentiative program of tumoral promyelocytes (Hsu et al., 1999; Visani et al., 1996). As a consequence of ATRA administration, tyrosine-phosphorylated Vav1 accumulates inside the nuclear compartment of APL-derived cells and becomes involved in the changes of nuclear morphology. Since local reorganization of nuclear architecture is required for both transcription and post-transcriptional events, it is conceivable that Vav1 plays a role in regulating ATRA-related gene expression.

An array analysis performed on HL-60 cells focussed on genes coding for cytokines and cytokine receptors indicates that the inhibition of the Syk-dependent tyrosinephosphorylation of Vav1 during ATRA treatment prevents the ATRA-induced expression of 8 genes (Bertagnolo et al., 2005). Among them, the thymosin beta-10 (TMSB10) gene has been found, encoding for a small G-actin binding protein that induces depolymerization of intracellular F-actin pools and thus deeply affects actin architecture (Liu et al., 2004; Rho et al., 2004). Tyrosine-phosphorylated Vav1 is also involved in regulating the ATRA-induced expression of the gene for Notch homolog, that codifies for a molecule playing a role in mediating cell fate decisions during hematopoiesis (Ohishi et al., 2003) and whose signaling might be necessary for the proliferation and survival of AML cells, possibly through the maintenance of the expression of $\mathrm{c}-\mathrm{Myc}$ and $\mathrm{Bcl} 2$, as well as the phosphorylation of the $\mathrm{Rb}$ protein (Li et al., 2010). The involvement of Vav1 in regulating ATRA-dependent expression of cytokines and/or growth factors has been ascertained by silencing Vav1 during ATRA admistration, further confirming that the increase of Vav1 expression is not an epiphenomenon but constitutes a key event able to actually promote the granulocytic maturation of tumoral myeloid precursors.

The evidence that Vav1 has a role in regulating ATRA-dependent gene expression in APLderived cells suggests the participation of Vav1 to transcriptional complexes activated by ATRA, also considering that, in both myeloid and lymphoid cells, Vav1 seems to be involved in regulating DNA transcription, by direct interaction with, or as a facilitator of, transcription factors (Katzav, 2004). In particular, Vav1 regulates Nuclear Factor of Activated T-cells (NFAT), Activator Protein-1 (AP-1) and Nuclear Factor кB (NF-кB) in Tcells in response to TCR stimulation, and exerts a specific role in regulating the CREBdependent gene transcription (Haubert \& Weckbecker, 2010; Schneider \& Rudd, 2008). Direct evidence for the presence of Vav1 as a component of an active transcriptional complex has been reported by Houlard et al. (2002) demonstrating the participation of Vav1 in complexes with NFAT and NF-kB-like, as facilitator of their transcriptional activity.

In APL-derived cells, nuclear Vav1 associates with PU.1 (Brugnoli et al., 2010), a transcription factor induced by ATRA and able to play a crucial role in the completion of granulocytic differentiation of APL-derived myeloid precursors (Mueller et al., 2006). In particular, the down-modulation of PU.1 by means of specific siRNAs has allowed to establish that, like in other tumoral myeloid precursors (Denkinger et al., 2002), PU.1 regulates the expression of Vav1 induced by ATRA in NB4 cells (Brugnoli et al., 2010).

In AML-derived myeloid precursors, PU.l represents a major determinant of the myeloid expression of CD11b (Kastner \& Chan, 2008; Pahl et al., 1993), an integrin receptor whose surface expression increases concurrently with CD11b mRNA levels during myeloid differentiation of APL-derived cell lines (Barber et al., 2008). Chromatin immunoprecipitation (ChIP) experiments performed on NB4 cells treated with ATRA have 
demonstrated that PU.1 is recruited to its consensus sequence within the CD11b promoter (Brugnoli et al., 2010). Since the over-expression of PU.1 might influence phenotype and restore differentiation of primary myeloid leukemic blasts (Durual et al., 2007), and its silencing counteracts the ATRA ability to induce the expression of the granulocytic marker CD11b (Mueller et al., 2006), PU.1 may be used by ATRA to promote CD11b expression during the late stages of the maturation of APL-derived cells. This is confirmed by in vitro experiments demonstrating the formation of PU.1-containing complexes on the CD11b promoter (Brugnoli et al., 2010).
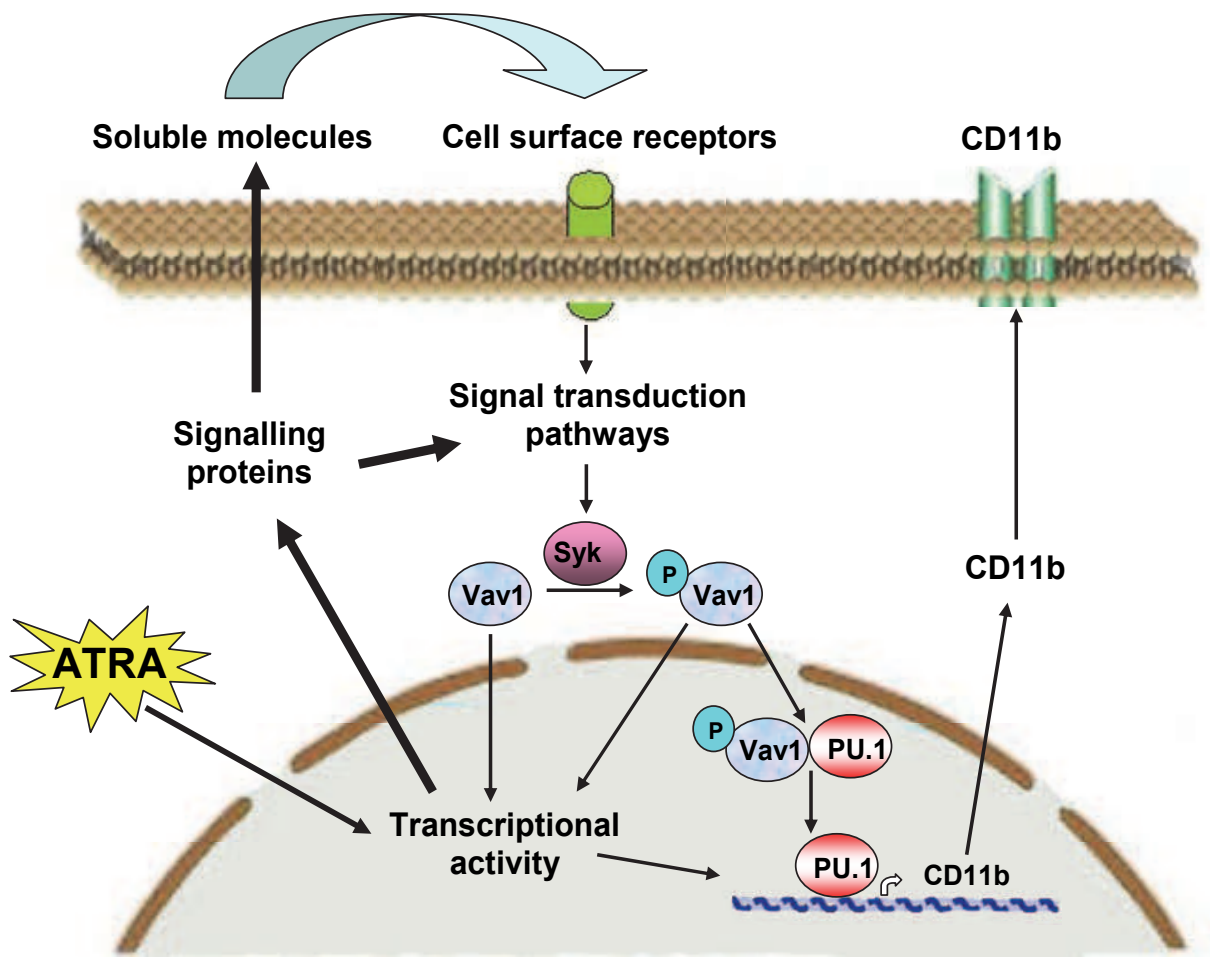

Fig. 2. Schematic representation of the involvement of Vav1 in regulating gene expression in differentiating promyelocytes.

Also Vav1 is recruited to the PU.1 consensus sequence on the CD11b promoter in untreated NB4 cells. ATRA treatment, by inducing an increase in Syk-dependent tyrosine phosphorylation of Vav1, displaces this protein from existing molecular complexes on the $C D 11 b$ promoter. Accordingly, the specific inhibition of Syk activity is accompanied by the appearance of a Vav1-containing complex (Brugnoli et al., 2010). The participation of Vav1 to molecular complexes including PU.1 has been ruled out by EMSA experiments. On the other hand, both expression and tyrosine phosphorylation levels of Vav1 seem to play a role in regulating the formation of PU.1-containing complexes. In fact, when the amount of Vav1 is forcedly reduced or its tyrosine phosphorylation is inhibited during the differentiation treatment, the formation of a PU.1-containing complex is negatively affected (Brugnoli et al., 
2010). It is then conceivable that Vav1, and in particular tyrosine-phosphorylated Vav1, regulates the recruitment of PU.1 to its consensus sequence on the CD11b promoter region and, possibly, the expression of this surface antigen.

\section{Vav1 and protein expression}

Proteome analysis currently provides the opportunity to identify global changes in gene expression by directly measuring protein amount. A number of recent studies have used this approach to evaluate protein expression during differentiation/apoptosis induced by different agonists in APL-derived cells. In particular, it has been reported that ATRA modulates the expression level of structural and signal transduction proteins as well as of molecules involved in the different phases of protein synthesis (Dong et al, 2006; Harris et al., 2004; Wan et al., 2001; Wang et al., 2004;).

On the basis of the evidence that inside the nucleus of a number of different cell lines, including APL-derived cells, Vav1 participates to molecular complexes with DNA-related proteins (Brugnoli et al., 2010; Houlard et al., 2002; Romero et al., 1998) a more general role of Vav1 in regulating events ended to control protein expression can be hypothesized. 2D electrophoresis followed by mass spectrometry have established that, in both HL-60 and NB4 cells, the down-modulation of Vav1 abrogates the capacity of ATRA of modulating the expression of proteins associated to cytoskeleton and involved in proliferation and of apoptosis-related proteins, as well as of molecules implicated in metabolism, synthesis, folding and degradation of proteins (Bertagnolo et al., 2008). The majority of the identified proteins are affected by Vav1 down-modulation only in one of the two analyzed cell lines, according to the notion that HL-60 and NB4 cells, even if both derived from patients with APL, show peculiar genotypic and phenotypic profiles (Barber et al., 2008). Interestingly, in NB4 cells, the lack of Vav1 affects the ATRA-dependent expression of the Splicing factor, arg/ser rich 3 (Sfrs3), a member of SR proteins, known as non-snRNP splicing factors, that may affect both constitutive and alternative splicing of mRNA (Sanford et al., 2005). This evidence further supports the role of Vav1 in regulating the ATRA-dependent gene expression.

Some of the identified proteins are differentially expressed, as a consequence of Vav1-downmodulation during ATRA treatment, in both cell lines, suggesting that they may constitute a common part of the signalling activated by ATRA in APL-derived promyelocytes. Notably, this group of proteins includes the $\varepsilon$ isoform of the 14-3-3 family of proteins, specifically involved in the caspase networks (Liou et al., 2007). The increased expression of 14-3-3e in both HL-60 and NB4 cells when Vav1 is down-modulated during ATRA treatment suggests that the amount of Vav1 may be critical in determining the mechanism of caspase activation in APL.

Vav1 also affects the ATRA-dependent expression of $\alpha$-enolase, a multifunction protein involved in glycolysis and up-regulated in the sera of a number of cancer patients, in which it seems to have a role in tumorigenesis (Zou et al., 2005). $\alpha$-enolase is expressed at high levels in most AML subtypes in which it might contribute to the adverse evolution of the disease (Lopez-Pedrera et al., 2006). Since down-modulation of Vav1 during ATRA treatment of APL-derived cells reduces the expression of $\alpha$-enolase (Bertagnolo et al., 2008), it has been suggested that Vav1 promotes the differentiation of tumoral promyelocytes by also targeting metabolic pathways. 
The proteasome component "splice isoform 2 subunit $\alpha 3$ " is down-modulated as well in HL-60 and NB4 cells under the same experimental conditions (Bertagnolo et al., 2008). Since proteasome is the major cellular proteolytic machinery responsible for degradation of normal and damaged proteins (Von Mikecz, 2006), Vav1 may also be involved in regulating protein degradation during ATRA dependent maturation of tumoral promyelocytes.

Also the component of microtubules $\alpha$-tubulin is affected by down-modulation of Vav1 during ATRA treatment (Bertagnolo et al., 2008), indicating that Vav1, in addition to regulate cytoskeleton reorganization, takes part to the profound architectural changes of differentiating promyelocytes by regulating the expression of cytoskeleton components.

\section{Vav1 and monocytic/macrophagic differentiation}

The human promyelocytic leukemia cell lines HL-60 and NB4 can be differentiated either toward neutrophils by ATRA or to monocytes/macrophages by PMA (Murao et al., 1983; Song \& Norman, 1998). PMA is a stable analogue of 2, 3-diacylglycerol that induces, even if with dynamics not identical in HL-60 and NB4 cells, morphological and functional changes related to monocyte maturation, accompanied by a loss of proliferative capacity (Jasek et al., 2008). Immunochemical and immunocytochemical analysis demonstrate that the expression of Vav1 increases also during the PMA-induced acquisition of a monocyte-like phenotype of HL-60 and NB4 cells (Bertagnolo et al., 2011). This is consistent with the notion that also mature monocytes express Vav1 and that proper amounts of the protein are necessary for their inflammation related functions (Bhavsar et al., 2009; Hall et al., 2006). In the same cell types, PMA also induces a relevant increase of tyrosine phosphorylation of Vav1. On the other hand, and in constrast to what observed in the ATRA-treatment of the same cell line, no role for Syk was demonstrated in this event (Bertagnolo et al., 2011), consistent with the notion that, at least in HL-60 cells, Syk might exert a narrower role, restricted to directing cells toward granulocyte differentiation (Qin \& Yamamura, 1997). In both HL-60 and NB4 cells, PMA induces a relevant increase of tyrosine phosphorylation of Vav1 on the Tyr174 residue (Bertagnolo et al., 2011), according to the GEF role played by Vav1 in myeloid cells. These results are also in agreement with other data indicating that, in macrophage-like differentiated HL-60 cells, the activity of Syk is ended to regulate the roles played by mature cells in immune response, including their complement-mediated phagocytosis, in which the kinase regulates both actin dynamics and the Vav1-RhoA activation pathway (Shi et al., 2006).

Also in differentiation of APL-derived cells to monocytes/macrophages, a crucial role for Vav1 in determining the acquisition of maturation-related features has been demonstrated by silencing the expression of Vav1 induced by PMA (Bertagnolo et al., 2011). Under these conditions, the expression of CD11b, which is induced by PMA and constitutes a marker also for monocyte differentiation, is significantly reduced, similarly to what demonstrated during the treatment with ATRA of HL-60 and NB4 cells (Bertagnolo et al. 2011). This suggests that, in differentiating APL-derived cells, Vav1 plays a role in regulating the expression of the $\mathrm{CD} 11 \mathrm{~b}$ surface antigen regardless the agonist employed and the maturation lineage. Since in NB4 cells treated with ATRA Vav1 is recuited to protein/DNA complexes on the CD11b promoter (Brugnoli et al., 2010), it can be speculated that Vav1 plays a specific role in driving the expression of CD11b as part of the transcriptional machinery also during the differentiation of NB4 cells along the monocytic/macrophagic lineage. 
Also cell adhesion is affected by down-modulation of Vav1 during PMA treatment of HL-60 and NB4 cells, in terms of both number of adherent cells and of adhesion area of cells that remain attached to the flask bottom. These results are in agreement with the data obtained with macrophages from Vav1-/- mice, showing a smaller adhesive area or a decreased adhesion efficiency (Wells et al., 2005).

\subsection{Regulation of actin}

As above reported, the main known functional role of tyrosine phosphorylated Vav1 is to regulate cytoskeleton reorganization, a phenomenon at the basis of both adhesion and migration of monocytes/macrophages. Vav1 regulates cell architecture not only by means of its GEF activity but also by interacting with proteins in turn involved in cytoskeleton reorganization. In addition, in both HL-60 and NB4 cells, Vav1 affects the ATRA-induced expression of the microtubule component $\alpha$-tubulin.

Contrarily to what observed during granulocytic differentiation, Vav1 down-modulation does not have any effect on expression and architectural organization of $\alpha$-tubulin during PMA-induced monocytic/macrophagic maturation of NB4 cells (Bertagnolo et al., 2011). This indicates that, during the maturation process of APL-derived cells, Vav1 exerts an agonist- and lineage-specific role in regulating $\alpha$-tubulin. From a more general point of view, concerning microtubule organization, it can be speculated that the role of Vav1 is restricted to the control of the motility of mature cells, as also suggested by the evidence that changes in microtubule dynamics contribute to the reduced migration speed of Vav1-/macrophages in response to CSF-1 (Wells et al., 2005).

In living cells, the F-actin cytoskeleton encompasses a variety of different structures that are essential for many different aspects of cell physiology. In particular, dynamic modulation of the filamentous actin cytoskeleton is critical to numerous physical cellular processes, including adhesion, migration and phagocytosis, all requiring precise regulation of cell shape (Stricker et al., 2010). Recent data demonstrate that Vav proteins, including Vav1, are required for actin cytoskeleton reorganization during migration of macrophages, by coupling RhoA and Rac1 activity to adhesion receptors (Bhavsar et al., 2009). Also in ATRAinduced maturation of cells derived from APL Vav1 seems to regulate actin organization.

In HL-60 and NB4 cells treated with PMA, an unprecedented involvement of Vav1 in regulating the increase of actin expression has been shown very recently (Bertagnolo et al., 2011), that constitutes a further confirmation that Vav1, besides being involved in the formation of filaments, takes part to cytoskeleton reorganization as a modulator of protein expression.

The modifications of cell shape in the different cell processes seem to be regulated by the existence of the F-actin cortex, a thin, membrane-bound F-actin network (Stricker et al., 2010). Defective actin-cap formation has been found in lymphocytes from a Vav-deficient mice, clearly correlating Vav1 activity with the regulation of cell shape (Holsinger et al., 1998). Furthermore, a recent work in which adhesive micropatterned surfaces have been used to control the overall shape of fibroblasts, has demonstrated that the shape of the nucleus is tightly regulated through a perinuclear actin cap, which is located above and around the interphase nucleus (Khatau et al., 2009). A wide variety of contractile F-actin networks with different architectures and polarity have also been found near cell adhesion surfaces, correlated with the migratory capability of adherent cells (Stricker et al., 2010). By means of confocal analysis of PMA-treated adherent NB4 cells, it has been demonstrated the 
existence of an agonist-induced F-actin network, in which F-actin colocalyzes with Vav1, that sharply defines the cytoplasmatic cell border, accumulates inside thin and long cell processes and surrounds the nuclear compartment (Bertagnolo et al., 2011). Since the existence of cytoplasmatic processes in PMA-treated adherent cells are indicative of migratory activity (Stricker et al., 2010), Vav1/F-actin co-localization in cytoplasm protrusions is suggestive of a synergy of the two molecules in controling cell motility. This is in agreement with the role described for Vav proteins in the maintenance of normal morphology and migratory behaviour in macrophages (Bhavsar et al., 2009). The strong Vav1/F-actin co-localization observed at the nuclear periphery and, in particular, in the region above the nucleus, suggests that the two proteins may cooperate in regulating the shape of the nucleus through an actin filament structure similar to the perinuclear actin cap described by Khatau et al. (2009). On the other hand, the role of Vav1 in modulating cell adhesion of PMA-treated cells seems to be related to its ability to regulate expression of integrins, like CD11b, rather than to a direct effect on actin-based cytoskeleton.

\section{Conclusion}

The present review focuses on the role of the multidomain protein Vav1 in promoting and sustaining the completion of the differentiation program of tumoral promyelocytes. Vav1 is a key protein in the ATRA- and PMA-induced maturation of APL-derived cells, since either its down-modulation or over-expression respectively prevents or potentiates the ability of these agonists to induce the acquisition of a mature phenotype. Alternatively to the best known function of Vav1 as a GEF for small G proteins, ended to regulate cell shape by affecting actin assembly, other mechanisms by which Vav1 affects myeloid differentiation have been described, reflecting the great interactive and regulatory potential of Vav1, which make the full understanding of its functions a very difficult, yet fascinating story.

An example of the complex role played by Vav1 during myeloid differentiation of APLderived cells is the interaction of Vav1 with various lipid-modifying enzymes ended to regulate the pool of phosphoinositides associated to cytoskeleton. The resulting modifications of actin cytoskeleton contribute to the changes of cellular and nuclear shape occurring in differentiating tumoral promyelocytes (Fig. 3).

The participation of Vav1 to molecular complexes with other adaptor proteins differently distributed in the cytoplasm and in the nucleus suggests the existence of a signal sequence originated from membrane receptors and directed to the nuclear compartment. Inside the nucleus of APL-derived cells, Vav1 seems to play its most intriguing role by regulating the expression of CD11b, a surface marker of both granulocyte and monocyte differentiation, and of a number of ATRA-modulated proteins (Fig. 3). The nuclear issue assumes thus great relevance, confering to Vav1 compartimentalized strategic roles in regulating the maturation process of tumoral promyelocytes.

The bulk of the studies reviewed here are mostly concerned with two cell lines, HL-60 and NB4, derived from APL patients, driven to achieve differentiation by treatment with drugs of the retinoids or phorbol esters families. Even though a better understanding of the functional engagement of Vav1 will be required before converting scientific achievements into clinical advances, Vav1 might be considered a common target for developing new therapeutic strategies for the different subtypes of myeloid leukemias.

In addition, it can be speculated that the identified pathways involving Vav1 are of more general interest and may be potentially extended also outside the haemopoietic/immunological systems. 


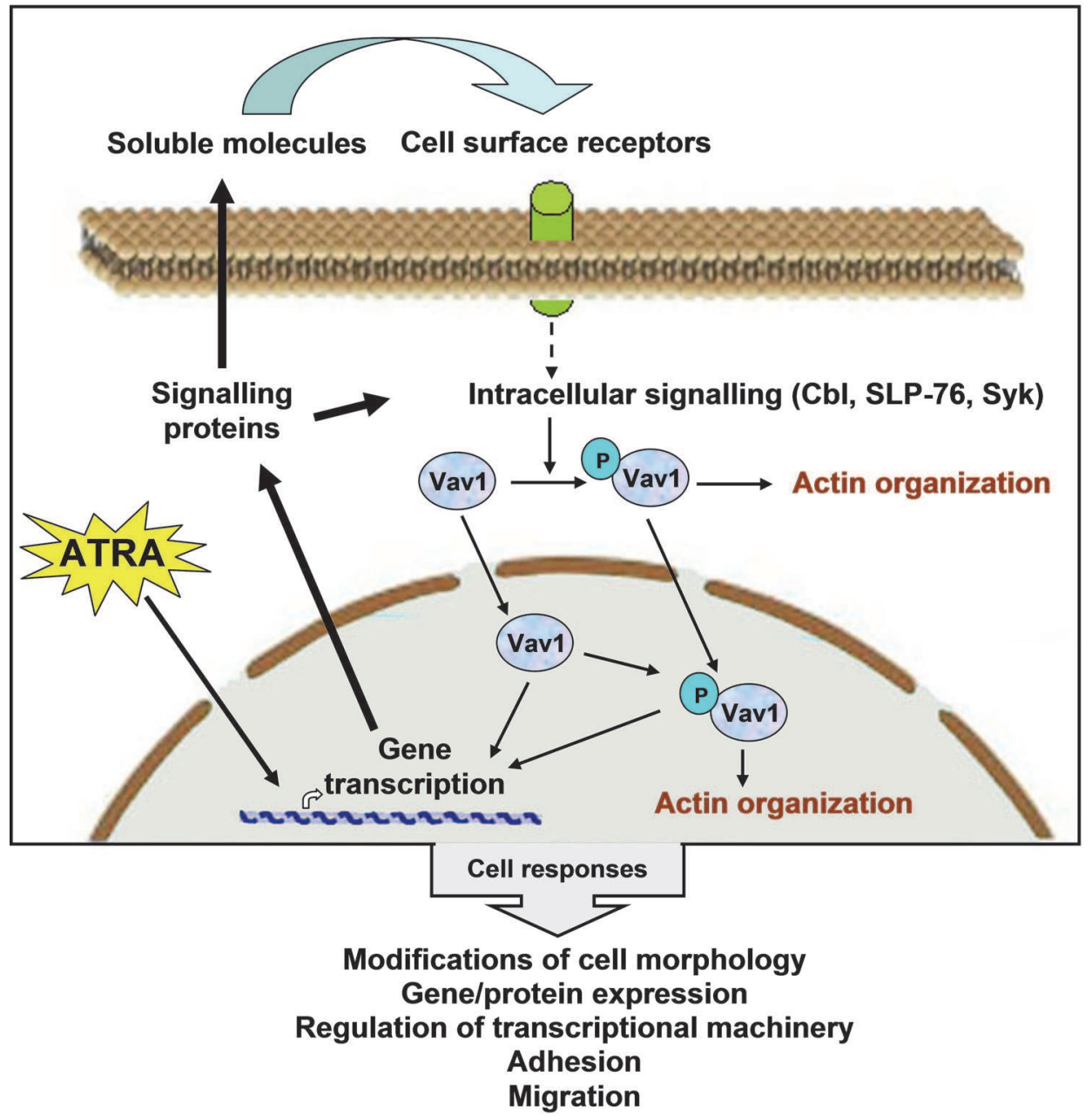

Fig. 3. Overall role of Vav1 in regulating maturation of APL-derived promyelocytes.

\section{Acknowledgments}

The authors are supported by MIUR (Cofin 2008 and FIRB Accordi di Programma 2010), MAE (Italy-Croatia bilateral project 2009-2011) and by University of Ferrara (Italy).

\section{References}

Barber, N., Belov, \& L., Christopherson, R.I. (2008). All-trans retinoic acid induces different immunophenotypic changes on human HL60 and NB4 myeloid leukaemias. Leukemia Research, Vol.32, No.2, (February 2008), pp. 315-322. 
Bertagnolo, V., Marchisio, M., Volinia, S., Caramelli, E. \& Capitani, S. (1998). Nuclear association of tyrosine-phosphorylated Vav to phospholipase C-gamma1 and phosphoinositide 3-kinase during granulocytic differentiation of HL-60 cells. FEBS Letters, Vol.441, No.3, (December 1998), pp. 480-484.

Bertagnolo, V., Neri, L.M., Marchisio, M., Mischiati, C. \& Capitani, S. (1999). Phosphoinositide 3-kinase activity is essential for all-trans-retinoic acid-induced granulocytic differentiation of HL-60 cells. Cancer Research, Vol. 59, No.3, (February 1999), pp. 542-546.

Bertagnolo, V., Marchisio, M., Brugnoli, F., Bavelloni, A., Boccafogli, L., Colamussi, M.L., \& Capitani, S. (2001). Requirement of tyrosine-phosphorylated Vav for morphological differentiation of all-trans-retinoic acid-treated HL-60 cells. Cell Growth $\mathcal{E}$ Differentiation, Vol.12,No.4, (April 2001), pp. 193-200.

Bertagnolo, V., Brugnoli, F., Marchisio, M., Celeghini, C., Carini, C., \& Capitani, S. (2004). Association of PI 3-K with tyrosine phosphorylated Vav is essential for its activity in neutrophil-like maturation of myeloid cells. Cellullar Signaling, Vol.16, No.4, (April 2004), pp. 423-433.

Bertagnolo, V., Brugnoli, F., Mischiati, C., Sereni, A., Bavelloni, A., Carini, C., \& Capitani, S. (2005). Vav promotes differentiation of human tumoral myeloid precursors. Experimental Cell Research, Vol.306, No.1, (May 2005), pp. 56-63.

Bertagnolo, V., Grassilli, S., Bavelloni, A., Brugnoli, F., Piazzi, M., Candiano, G., Petretto, A., Benedusi, M., \& Capitani, S. (2008). Vav1 modulates protein expression during ATRA-induced maturation of APL-derived promyelocytes: a proteomic-based analysis. Journal of Proteome Research, Vol. 7, No.9, (September 2008), pp. 3729-3736.

Bertagnolo, V., Grassilli, S., D'Aguanno, S., Brugnoli, F., Bavelloni, A., Faenza, I., Nika, E., Urbani, A., Cocco, L., \& Capitani, S. (2010). Mass spectrometry-based identification of Y745 of Vav1 as a tyrosine residue crucial in maturation of acute promyelocytic leukemia-derived cells. Journal of Proteome Research, Vol.9, No.2, (February 2010), pp. 752-760.

Bertagnolo, V., Nika, E., Brugnoli, F., Bonora, M., Grassilli, S., Pinton, P., \& Capitani, S. (2011). Vav1 is a crucial molecule in monocytic/macrophagic differentiation of myeloid leukemia-derived cells. Cell and Tissue Research, [Epub ahead of print], (June 2011), DOI: 10.1007/s00441-011-1195-5.

Bhavsar, P.J., Vigorito, E., Turner, M., \& Ridley, A.J. (2009). Vav GEFs regulate macrophage morphology and adhesion-induced Rac and Rho activation. Experimental Cell Research, Vol.315, No.19, (November 2009), pp. 3345-3358.

Breitman, T.R., Selonick, S.E., \& Collins, S.J. (1980). Induction of differentiation of the human promyelocytic leukemia cell line (HL-60) by retinoic acid. Proceedings of the National Academy of Sciences of the United States of America, Vol.77, No.5, (May 1980), pp. 2936-2940.

Brugnoli, F., Lambertini, E., Varin-Blank, N., Piva, R., Marchisio, M., Grassilli, S., Miscia, S., Capitani, S., \& Bertagnolo, V. (2010). Vav1 and PU.1 are recruited to the CD11b promoter in APL-derived promyelocytes: role of Vav1 in modulating PU.1containing complexes during ATRA-induced differentiation. Experimental Cell Research, Vol.316, No.1, (January 2010), pp. 38-47. 
Bustelo, X. R., Crespo, P., Lopez-Barahona, M., Gutkind, J. S., \& Barbacid, M. (1997). Cbl-b, a member of the Sli-1/c-Cbl protein family, inhibits Vav-mediated c-Jun N-terminal kinase activation. Oncogene, Vol.15, No.21, (November 1997), pp. 2511-2520, 1997.

Bustelo, X.R. (2001). Vav proteins, adaptors and cell signaling. Oncogene, Vol.20, No.44, (October 2001), pp. 6372-6381.

Bustelo, X.R. (2002). Regulation of Vav proteins by intramolecular events. Frontiers in Biosciences, Vol.7, (January 2002), pp. 24-30.

Chen, L., Janetopoulos, C., Huang, Y.E., Iijima, M., Borleis, J., \& Devreotes, P.N. (2003). Two phases of actin polymerization display different dependencies on $\mathrm{PI}(3,4,5) \mathrm{P} 3$ accumulation and have unique roles during chemotaxis. Molecular Biology of the Cell, Vol.14, No.12, (December 2003), pp. 5028-5037.

Chiang, J., \& Hodes, R.J. (2011). Cbl Enforces Vav1 Dependence and a Restricted Pathway of T Cell Development. PLoS ONE, Vol.6, No.4, (April 2011), e18542.

Cicchetti, G., Allen, P.G., \& Glogauer, M. (2002). Chemotactic signaling pathways in neutrophils: From receptor to actin assembly. Critical Reviews in Oral Biology $\mathcal{E}$ Medicine, Vol.13, No.3, (May 2002), pp. 220-228.

Clevenger, C.V., Ngo, W., Sokol, D.L., Luger, S.M. \& Gewirtz, A.M. (1995). Vav is necessary for prolactin-stimulated proliferation and is translocated into the nucleus of T-cell line. The Journal of Biological Chemistry, Vol.270, No.22, (June 1995), pp. 13246-13253.

Congleton, J., Jiang, H., Malavasi, F., Lin, H., \& Yen, A. (2011). ATRA-induced HL-60 myeloid leukemia cell differentiation depends on the CD38 cytosolic tail needed for membrane localization, but CD38 enzymatic activity is unnecessary. Experimental Cell Research, Vol.317, No.7, (April 2011), pp. 910-919.

Cougoule, C., Hoshino, S., Dart, A., Lim, J., \& Caron, E. (2006). Dissociation of recruitment and activation of the small G-protein Rac during Fcgamma receptor-mediated phagocytosis. The Journal of Biological Chemistry, Vol.281, No.13, (March 2006), pp. 8756-8764.

Cui, L., Chen, C., Xu, T., Zhang, J., Shang, X., Luo, J., Chen, L., Ba, X., \& Zeng, X. (2009). c$\mathrm{Abl}$ kinase is required for beta 2 integrin-mediated neutrophil adhesion. Journal of Immunology, Vol.182, No.5, (March 2009), pp. 3233-3242.

Daniels, R.H., \& Bokoch, G.M. (1999). p21-activated protein kinase: a crucial component of morphological signaling? Trends in Biochemical Sciences, Vol.24, No.9, (September 1999), pp. 350-355.

Denkinger, D.J., Lambrecht, T.Q., Cushman-Vokoun, \& A.M., Kawahara, R.S. (2002). PU.1 regulates the expression of the vav proto-oncogene. Journal of Cellular Biochemistry, Vol.84, No.4, (January 2002), pp. 772-783.

Dong, H., Ying, T., Li, T., Cao, T., Wang, J., Yuan, J., Feng, E., Han, B., Hua, F., Yang, Y., Yuan, J., Wang, H., \& Xu, C. (2006). Comparative proteomic analysis of apoptosis induced by sodium selenite in human acute promyelocytic leukemia NB4 cells. Journal of Cellular Biochemistry, Vol.98, No.9, (August 2006), pp. 1495-1506.

Durual, S., Rideau, A., Ruault-Jungblut, S., Cossali, D., Beris, P., Piguet, V., \& Matthes T. (2007). Lentiviral PU.1 overexpression restores differentiation in myeloid leukemic blasts. Leukemia, Vol.21, No.5, (May 2007), pp. 1050-1059. 
Fischer, K.D., Kong, Y.Y., Nishina, H., Tedford, K., Marengère, L.E., Kozieradzki, I., Sasaki, T., Starr, M., Chan, G., Gardener, S., Nghiem, M.P., Bouchard, D., Barbacid, M., Bernstein, A., \& Penninger, J.M. (1998). Vav is a regulator of cytoskeletal reorganization mediated by the T-cell receptor. Current Biology, Vol.8, No.10, (May 1998), pp. 554-562.

Fujikawa, K., Miletic, A.V., Alt, F.W., Faccio, R., Brown, T., Hoog, J., Fredericks, J., Nishi, S., Mildiner, S., Moores, S.L., Brugge, J., Rosen, F.S., \& Swat, W. (2003) Vav1/2/3-null mice define an essential role for Vav family proteins in lymphocyte development and activation but a differential requirement in MAPK signaling in $\mathrm{T}$ and B cells. The Journal of Experimental Medicine, Vol.198, No.10, (November 2003), pp. 15951608.

Gakidis, M.A., Cullere, X., Olson, T., Wilsbacher, J.L., Zhang, B., Moores, S.L., Ley, K., Swat, W., Mayadas, T., \& Brugge, J.S. (2004). Vav GEFs are required for beta2 integrindependent functions of neutrophils. The Journal of Cell Biology, Vol.166, No.2, (July 2004), pp. 273-282.

Gomez, T. S., Hamann, M. J., McCarney, S., Savoy, D. N., Lubking, C. M., Heldebrant, M. P., Labno, C. M., McKean, D. J., McNiven, M. A., Burkhardt, J. K. \& Billadeau, D. D. (2005). Dynamin 2 regulates T cell activation by controlling actin polymerization at the immunological synapse. Nature Immunology, Vol.6, No.3, (March 2005), pp. 261270.

Gross, B. S., Ran Lee, J., Clements, J. L., Turner, M., Tybulewicz,V. L. J., Findell, P. R., Koretzky, G. A., \& Watson, S. P. (1999). Tyrosine phosphorylation of SLP-76 is downstream of Syk following stimulation of the collagen receptor in platelets. The Journal of Biological Chemistry, Vol.274, No.9, (February 1999), pp. 5963-5971.

Hall, A.B., Gakidis, M.A., Glogauer, M., Wilsbacher, J.L., Gao, S., Swat, W., \& Brugge, J.S. (2006). Requirements for Vav guanine nucleotide exchange factors and Rho GTPases in FcgammaR- and complement-mediated phagocytosis. Immunity, Vol.24, No.3, (March 2006), pp. 305-316.

Han, J., Luby-Phelps, K., Das, B., Shu, X., Xia, Y., Mosteller, R.D., Krishna, U.M., Falck, J.R., White, M.A., \& Broek, D. (1998). Role of substrates and products of PI 3-kinase in regulating activation of Rac-related guanosine triphosphatases by Vav. Science, Vol.279, No.5350, (January 1998), pp. 558-560.

Hannigan, M., Zhan, L., Li, Z., Ai, Y., Wu, D., Huang, C.K. (2002). Neutrophils lacking phosphoinositide 3-kinase gamma show loss of directionality during $N$-formylMet-Leu-Phe-induced chemotaxis. Proceedings of the National Academy of Sciences of the United States of America, Vol.99, No.6, (March 2002), pp. 3603-3608.

Harris, M.N., Ozpolat, B., Abdi, F., Gu, S., Legler, A., Mawuenyega, K.G., Tirado-Gomez, M., Lopez-Berestein, G., \& Chen, X.(2004). Comparative proteomic analysis of alltrans-retinoic acid treatment reveals systematic posttranscriptional control mechanisms in acute promyelocytic leukemia. Blood, Vol.104, No.5, (September 2004), pp. 1314-1323.

Haubert, D., \& Weckbecker, G. (2010). Vav1 couples the T cell receptor to cAMP response element activation via a PKC-dependent pathway. Cellular Signaling, Vol.22, No.6, (June 2010), pp. 944-954. 
Holsinger, L.J., Graef, I.A., Swat, W., Chi, T., Bautista, D.M., Davidson, L., Lewis, R.S., Alt, F.W., \& Crabtree, G.R. (1998). Defects in actin-cap formation in Vav-deficient mice implicate an actin requirement for lymphocyte signal transduction. Current Bioloogy, Vol.8, No.10, (May 1998), pp. 563-572.

Hornstein, I., Alcover, A., \& Katzav, S. (2004). Vav proteins, masters of the world of cytoskeleton organization. Cellular Signalling Vol.16, No.1, (January 2004), pp. 1-11.

Houlard, M., Arudchandran, R., Regnier-Ricard, F., Germani, A., Gisselbrecht, S., Blank, U., Rivera, J., \& Varin-Blank, N. (2002). Vav1 is a component of transcriptionally active complexes.The Journal of Experimental Medicine, Vol.195, No.9, (May 2002), pp. 11151127.

Hsu, H.C., Tsai, W.H., Chen, P.G., Hsu, M.L., Ho, C.K., \& Wang, S.Y. (1999). In vitro effect of granulocyte-colony stimulating factor and all-trans retinoic acid on the expression of inflammatory cytokines and adhesion molecules in acute promyelocytic leukemic cells. European Journal of Haematology, Vol.63, No.1, (July 1999), pp.11-18.

Janmey, P.A., Xian, W., \& Flanagan, L.A. (1999). Controlling cytoskeleton structure by phosphoinositide-protein interactions: phosphoinositide binding protein domains and effects of lipid packing. Chemistry and Physics of Lipids, Vol.101, No.1, (August 1999), pp. 93-107.

Jasek, E., Mirecka, J., \& Litwin, J.A. (2008). Effect of differentiating agents (all-trans retinoic acid and phorbol 12-myristate 13-acetate) on drug sensitivity of HL60 and NB4 cells in vitro. Folia Histochemica et Cytobiologica, Vol.46, No.3, (December 2008), pp.323330, ISSN, 0239-8508.

Kastner P., \& Chan, S. (2008). PU.1: a crucial and versatile player in hematopoiesis and leukemia. The International Journal of Biochemistry and Cell Biology, Vol.40, No.1, (n.d.), pp. 22-27.

Katzav, S. (2004). Vav1: an oncogene that regulates specific transcriptional activation of T cells. Blood, Vol.103, No.7, (April 2004), pp. 2443-2451.

Katzav, S. (2009). Vav1: a hematopoietic signal transduction molecule involved in human malignancies. The International Journal of Biochemistry \& Cell Biology, Vol.41, No.6, (June 2009), pp. 1245-1248.

Khatau, S.B., Hale, C.M., Stewart-Hutchinson, P.J., Patel, M.S., Stewart, C.L., Searson, P.C., Hodzic, D., \& Wirtz, D. (2009). A perinuclear actin cap regulates nuclear shape. Proceedings of the National Academy of Sciences of the United States of America, Vol.106, No.45, (November 2009), pp. 19017-19122.

Kim, C., Marchal, C.C., Penninger, J. \& Dinauer M.C. (2003). The hemopoietic Rho/Rac guanine nucleotide exchange factor Vav1 regulates $\mathrm{N}$-formyl-methionyl-leucylphenylalanine-activated neutrophil functions. Journal of Immunology, Vol.171, No.8, (October 2003), pp. 4425-4430.

Kogan, S.C. (2009). Curing APL: differentiation or destruction? Cancer Cell, Vol.15, No.1, (January 2009), pp. 7-8.

Kong, Y.Y., Fischer, K.D., Bachmann, M.F., Mariathasan, S., Kozieradzki, I., Nghiem, M.P., Bouchard, D., Bernstein, A., Ohashi, P.S. \& Penninger, J.M. (1998). Vav regulates peptide-specific apoptosis in thymocytes. The Journal of Experimental Medicine,Vol.188, No.11, (December 1998), pp. 2099-2111. 
Lamkin T.J., Chin, V., Varvayanis, S., Smith, J.L., Sramkoski, R.M., Jacobberger, J.W., \& Yen, A. (2006). Retinoic acid-induced CD38 expression in HL-60 myeloblastic leukemia cells regulates cell differentiation or viability depending on expression levels. Journal of Cellular Biochemistry, Vol.97, No.6, (April 2006), pp. 1328-1338.

Lanotte M., Martin-Thouvenin, V., Najman, S. Balerini, P., Valensi, F., \& Berger, R. (1991). NB4, a maturation inducible cell line with $\mathrm{t}(15 ; 17)$ marker isolated from a human acute promyelocytic leukemia (M3). Blood, Vol.77, No.5, (March 1991), pp. 10801086.

Law, D. A., Nannizzi-Alaimo, L., Ministri, K., Hughes, P. E., Forsyth, J.,Turner, M., Shattil, S. J., Ginsberg, M. H., Tybulewicz, V. L. J., \& Phillips,D. R. (1999). Genetic and pharmacological analyses of Syk function in aII-b3 signaling in platelets. Blood, Vol.93, No.8, (April 1999), pp. 2645-2652.

Lazer, G., Pe'er, L., Farago, M., Machida, K., Mayer, B.J., \& Katzav, S. (2010). Tyrosine residues at the carboxyl terminus of Vav1 play an important role in regulation of its biological activity. The Journal of Biological Chemistry, Vol.285, No.30, (July 2010), pp. 23075-23085.

Li, G.H., Fan, Y.Z., Liu, X.W., Zhang, B.F., Yin, D.D., He, F., Huang, S.Y., Kang, Z.J., Xu, H., Liu, Q., Wu, Y.L., Niu, X.L., Zhang, L., Liu, L., Hao, M.W., Han, H., \& Liang, Y.M. (2010). Notch signaling maintains proliferation and survival of the HL60 human promyelocytic leukemia cell line and promotes the phosphorylation of the $\mathrm{Rb}$ protein. Molecular and Cellular Biochemistry, Vol.340, No. 1-2, (July 2010), pp. 7-14.

Liou, J.Y., Ghelani, D., Yeh, S., \& Wu, K.K. (2007). Nonsteroidal anti-inflammatory drugs induce colorectal cancer cell apoptosis by suppressing 14-3-3epsilon. Cancer Research, Vol.67, No.7, (April 2007), pp. 3185-3191.

Liu, C.R., Ma, C.S., Ning, J.Y., You, J.F., Liao, S.L., \& Zheng, J. (2004). Differential thymosin beta 10 expression levels and actin filament organization in tumor cell lines with different metastatic potential. Chinese Medical Journal, Vol.117, No.2, (February 2004), pp. 213- 218.

Lo-Coco F., \& Ammatuna, E. (2006). The biology of acute promyelocytic leukemia and its impact on diagnosis and treatment. Hematology, (January 2006), pp. 156-161.

López-Pedrera, C., Villalba, J.M., Siendones, E., Barbarroja, N. Gómez-Díaz, C., RodríguezAriza, A., Buendía, P., Torres, A., \& Velasco, F. (2006). Proteomic analysis of acute myeloid leukemia: Identification of potential early biomarkers and therapeutic targets. Proteomics, Vol.6, No.S1, (April 2006), pp. 293-299.

Lupher, M.L., Jr., Rao, N., Eck, M.J., \& Band, H. The Cbl protooncoprotein: a negative regulator of immune receptor signal transduction. Immunology Today, Vol.20, No.8, (August 1999), pp. 375-382.

Menard, R.E., \& Mattingly, R.R. (2004). Gbetagamma subunits stimulate p21-activated kinase 1 (PAK1) through activation of PI3-kinase and Akt but act independently of Rac1/Cdc42. FEBS Letters, Vol.556, No.1-3, (January 2004), pp. 187-192.

Miletic, A.V., Sakata-Sogawa, K., Hiroshima, M., Hamann, M.J., Gomez, T. S., Ota, N., Kloeppel, T., Kanagawa, O., Tokunaga, M., Billadeau, D.D., \& Swat, W. (2006). Vav1 acidic region tyrosine 174 is required for the formation of $\mathrm{T}$ cell receptor- 
induced microclusters and is essential in T cell development and activation. The Journal of Biological Chemistry, Vol.281, No.50, (December 2006), pp. 38257-38265.

Mueller, B.U., Pabst, T., Fos, J., Petkovic, V., Fey, M.F., Asou, N., Buergi, U., \& Tenen, D.G. (2006). ATRA resolves the differentiation block in $t(15 ; 17)$ acute myeloid leukemia by restoring PU.1 expression. Blood, Vol.107, No.8, (April 2006), pp. 3330-3338.

Murao, S., Gemmell, M.A., Callaham, M.F., Anderson, N.L., \& Huberman, E. (1983). Control of macrophage cell differentiation in human promyelocytic HL-60 leukemia cells by 1,25-dihydroxyvitamin D3 and phorbol-12-myristate-13-acetate. Cancer Research, Vol.43, No.10, (October 1983), pp. 4989-4996.

Nasr, R., Guillemin, M.C., Ferhi, O., Soilihi, H., Peres, L., Berthier, C., Rousselot, P., RobledoSarmiento, M., Lallemand-Breitenbach, V., Gourmel, B., Vitoux, D., Pandolfi, P.P., Rochette-Egly, C., Zhu, J., \& de Thé, H. (2008). Eradication of acute promyelocytic leukemia-initiating cells through PML-RARA degradation. Nature Medicine, Vol.14, No.12, (December 2008), pp. 1333-1342.

Niggli, V., \& Keller, H. (1997). The phosphatidylinositol 3-kinase inhibitor wortmannin markedly reduces chemotactic peptide-induced locomotion and increases in cytoskeletal actin in human neutrophils. European Journal of Pharmacology, Vol.335, No.1, (September 1997), pp. 43-52.

Ohishi, K., Katayama, N., Shiku, H., Varnum-Finney, B., \& Bernstein, I.D. (2003). Notch signalling in hematopoiesis. Seminars in Cell \& Developmental Biology, Vol.14, No.2, (April 2003), pp. 143- 150.

Ottinger, E., Botfield, M.C., \& Shoelson, S.E. (1998). Tandem SH2 domains confer high specificity in tyrosine kinase signaling. The Journal of Biological Chemistry, Vol.273, No.2, (January 1998), pp. 729-735.

Pahl H.L., Scheibe, R.J., Zhang, D.E., Chen, H.M., Galson, D.L., Maki, R.A., \& Tenen, D.G. (1993). The proto-oncogene PU.1 regulates expression of the myeloid-specific CD11b promoter. The Journal of Biological Chemistry, Vol.268, No.7, (March 1993), pp. 5014-5020.

Pauker, M.H., \& Barda-Saad, M. (2011). Studies of novel interactions between Nck and VAV SH3 domains. Communicative E Integrative Biology, Vol.4, No.2, (March/ April 2011), pp. 175-177.

Phillipson, M., Heit, B., Parsons, S.A., Petri, B., Mullaly, S.C., Colarusso, P., Gower, R.M., Neely, G., Simon, S.I., \& Kubes, P. (2009). Vav1 is essential for mechanotactic crawling and migration of neutrophils out of the inflamed microvasculature. Journal of Immunology, Vol.182, No.11, (June 2009), pp. 6870-6878.

Pivniouk, V.I., Martin, T.R., Lu-Kuo, J.M., Katz, H.R., Oettgen, H.C., \& Geha, R.S. (1999). SLP-76 deficiency impairs signaling via the high-affinity IgE receptor in mast cells. The Journal of Clinical Investigation, Vol.103, No.12, (June 1999), pp. 1737-1743.

Qin, S., \& Yamamura, H. (1997). Up-regulation of Syk activity during HL60 cell differentiation into granulocyte but not into monocyte/macrophage-lineage. Biochemical and Biophysical Ressearch Communications, Vol.236, No.3, (July 1997), pp. 697-701.

Rho, S.B., Chun, T., Lee, S.H., Park, K., \& Lee, J.H. (2004). The interaction between Etropomodulin and thymosin beta-10 rescues tumor cells from thymosin beta-10 
mediated apoptosis by restoring actin architecture. FEBS Letters, Vol.557, No.1-3, (January 2004), pp. 57-63.

Romero, F., Dargemont, C., Pozo, F., Reeves, W.H., Camonis, J., Gisselbrecht, S., \& Fischer S. (1996). p95vav associates with the nuclear protein Ku-70. Molecular and Cellular Biology, Vol.16, No.1, (January 1996), pp. 37-44.

Romero, F., Germani, A., Puvion, E., Camonis, J., Varin-Blank, N., Gisselbrecht, S., \& Fischer, S. (1998). Vav binding to heterogeneous nuclear ribonucleoprotein (hnRNP) C. Evidence for Vav-hnRNP interactions in an RNA-dependent manner. The Journal of Biological Chemistry, Vol.273, No.10, (March 1998), pp. 5923-5931.

Sanchez, J.A., \& Wangh, L.J. (1999). New insights into the mechanisms of nuclear segmentation in human neutrophils. Journal of Cellular Biochemistry, Vol.73, No.1, (April 1999), pp. 1-10.

Sanchez-Aguilera, A., Lee, Y.J., Lo Celso, C., Ferraro, F., Brumme, K., Mondal, S., Kim, C., Dorrance, A., Luo, H.R., Scadden, D.T, \& Williams D.A. (2011). Guanine nucleotide exchange factor Vav1 regulates perivascular homing and bone marrow retention of hematopoietic stem and progenitor cells. Proceedings of the National Academy of Sciences of the United States of America, Vol.108, No.23, (June 2011), pp. 9607-9612.

Sanford, J.R., Ellis, J., \& Cáceres, J.F. (2005). Multiple roles of arginine/serine-rich splicing factors in RNA processing. Biochemical Society Transactions, Vol.33, No.3, (June 2005), pp. 443-446.

Schneider H., \&. Rudd, C.E. (2008). CD28 and Grb-2, relative to Gads or Grap, preferentially co-operate with Vav1 in the activation of NFAT/AP-1 transcription. Biochemical and Biophysical Ressearch Communications, Vol.369, No.2, (May 2008), pp. 616-621.

Schymeinsky, J., Sindrilaru, A., Frommhold, D., Sperandio, M., Gerstl, R., Then, C., Mócsai, A., Scharffetter-Kochanek, K., \& Walzog, B. (2006). The Vav binding site of the nonreceptor tyrosine kinase Syk at Tyr 348 is critical for beta2 integrin (CD11/CD18)mediated neutrophil migration. Blood, Vol.108, No.12, (December 2006), pp. 39193927.

Seow C.J., Chue, S.C., \& Wong, W.S. (2002). Piceatannol, a Syk-selective tyrosine kinase inhibitor, attenuated antigen challenge of guinea pig airways in vitro. European Journal of Pharmacology, Vol.443, No.1-3, (May 2002), pp. 189-196.

Shi, Y., Tohyama, Y., Kadono, T., He, J., Miah, S.M., Hazama, R., Tanaka, C., Tohyama, K., \& Yamamura, H. (2006). Protein-tyrosine kinase Syk is required for pathogen engulfment in complement-mediated phagocytosis. Blood, Vol.107, No.11, (June 2006), pp. 4554-4562.

Song, X., \& Norman, A.W. (1998). 1Alpha,25-dihydroxyvitamin D3 and phorbol ester mediate the expression of alkaline phosphatase in NB4 acute promyelocytic leukemia cells. Leukemia Research, Vol.22, No.1, (January 1998), pp. 69-76.

Stephens, L., Ellson, C., \& Hawkins, P. (2002). Roles of PI3Ks in leukocyte chemotaxis and phagocytosis. Current Opinion in Cell Biology, Vol.14, No.2, (April 2002), pp. 203213.

Stricker, J., Falzone, T., \& Gardel, M.L. (2010). Mechanics of the F-actin cytoskeleton. Journal of Biomechanics, Vol.43, No.1, (January 2010), pp. 9-14. 
Takenawa, T., \& Itoh, T. (2001). Phosphoinositides, key molecules for regulation of actin cytoskeletal organization and membrane traffic from the plasma membrane. Biochimica et Biophysica Acta, Vol.1533, No.3, (October 2001), pp. 190-106.

Tallman, M. (2007). Treatment of relapsed or refractory acute promyelocytic leukemia. Best Practice E Research Clinical Haematology, Vol.20, No.1, (March 2007), pp. 57-65.

Tuosto, L., Michel, F., \& Acuto, O. (1996). p95vav associates with tyrosine-phosphorylated SLP-76 in antigen-stimulated T cells. The Journal of Experimental Medicine, Vol.184, No.3, (September 1996), pp. 1161-1166.

Tybulewicz, V.L. (2005). Vav-family proteins in T-cell signalling. Current Opinion in Immunology, Vol.17, No.3, (June 2005), 267-274.

Vedham, V., Phee, H., \& Coggeshall, K.M. (2005). Vav activation and function as a rac guanine nucleotide exchange factor in macrophage colony-stimulating factorinduced macrophage chemotaxis. Molecular and Cellular Biology, Vol.25, No.10, (May 2005), pp. 4211-4220.

Visani, G., Tosi, P., Ottaviani, E., Zaccaria, A., Baccini, C., Manfroi, S., Pastano, R., Remiddi, C., Morelli, A., Molinari, A.L., Zanchini, R., \& Tura, S. (1996). All-trans retinoic acid and in vitro cytokine production by acute promyelocytic leukemia cells. European Journal of Haematology, Vol.57, No.4, (October 1996), pp. 301-306.

Von Mikecz, A. (2006). The nuclear ubiquitin-proteasome system. Journal of Cell Science, Vol.119, No.10, (May 2006), pp. 1977-1984.

Wan, J., Wang, J., Cheng, H., Yu, Y. Xing, G., Oiu, Z., Qian, X., \& He, F.(2001). Proteomic analysis of apoptosis initiation induced by all-trans retinoic acid in human acute promyelocytic leukemia cells. Electrophoresis, Vol.22, No.14, (August 2001), pp. 3026-3037.

Wang, D., Jensen, R., Gendeh, G., Williams, K. \& Pallavicini, M.G. (2004). Proteome and transcriptome analysis of retinoic acid-induced differentiation of human acute promyelocytic leukemia cells, NB4. Journal of Proteome Research, Vol.3, No.3, (MayJune 2004), pp. 627-635.

Wang, F., Herzmark, P., Weiner, O.D., Srinivasan, S., Servant, G., \& Bourne, H.R. (2002). Lipid products of PI3Ks maintain persistent cell polarity and directed motility in neutrophils. Nature Cell Biology, Vol.4, No.7, (July 2002), pp. 513-518.

Wells, C.M., Bhavsar, P.J., Evans, I.R., Vigorito, E., Turner, M., Tybulewicz, V., \& Ridley A.J. (2005). Vav1 and Vav2 play different roles in macrophage migration and cytoskeletal organization. Experimental Cell Research, Vol.1, No.2, (November 2005), pp. 303-310.

Yang, L., Zhao, H., Li, S.W., Ahrens, K., Collins, C., Eckenrode, S., Ruan, Q.G., McIndoe, R.A., \& She, J.X. (2003). Gene expression profiling during all-trans retinoic acidinduced cell differentiation of acute promyelocytic leukemia cells. The Journal of Molecular Diagnostics, Vol.5, No.4, (November 2003), pp. 212-221.

Yu, B., Martins, R.S., Li, P., Amarasinghe, G.K., Umetani, J., Fernandez-Zapico, M.E., Billadeau,D.D., Machius, M., Tomchick, D.R., Rosen, M.K. (2010). Structural and Energetic Mechanisms of Cooperative Autoinhibition and Activation of Vav1. Cell, Vol.140, (January 22), pp. 246-256. 
Zhang, R., Tsai, F.Y., \& Orkin, S.H. (1994). Hematopoietic development of vav-/- mouse embryonic stem cells. Proceedings of the National Academy of Sciences of the United States of America Vol.91, No.26, (December 1994), pp. 12755-12759.

Zou, L., Wu, Y., Pei, L., Zhong, D., Gen, M., Zhao, T., Wu, J., Ni, B., Mou, Z., Han, J., Chen, Y., Zhi, Y. (2005). Identification of leukemia-associated antigens in chronic myeloid leukemia by proteomic analysis. Leukemia Research, Vol.29, No.12, (December 2005), pp. 1387-1391. 


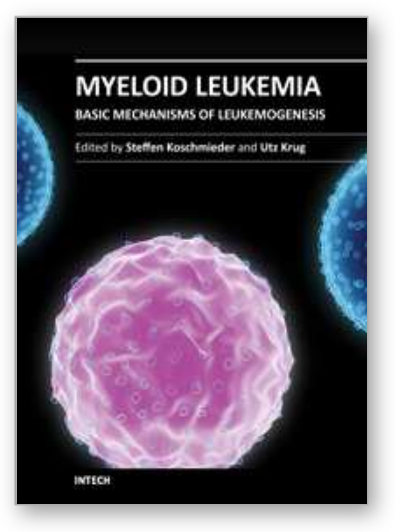

\author{
Myeloid Leukemia - Basic Mechanisms of Leukemogenesis \\ Edited by Dr Steffen Koschmieder
}

ISBN 978-953-307-789-5

Hard cover, 484 pages

Publisher InTech

Published online 14, December, 2011

Published in print edition December, 2011

The current book comprises a series of chapters from experts in the field of myeloid cell biology and myeloid leukemia pathogenesis. It is meant to provide reviews about current knowledge in the area of basic science of acute $(A M L)$ and chronic myeloid leukemia $(C M L)$ as well as original publications covering specific aspects of these important diseases. Covering the specifics of leukemia biology and pathogenesis by authors from different parts of the World, including America, Europe, Africa, and Asia, this book provides a colorful view on research activities in this field around the globe.

\title{
How to reference
}

In order to correctly reference this scholarly work, feel free to copy and paste the following:

Valeria Bertagnolo, Federica Brugnoli and Silvano Capitani (2011). Vav1: A Key Player in Agonist-Induced Differentiation of Promyelocytes from Acute Myeloid Leukemia (APL), Myeloid Leukemia - Basic Mechanisms of Leukemogenesis, Dr Steffen Koschmieder (Ed.), ISBN: 978-953-307-789-5, InTech, Available from: http://www.intechopen.com/books/myeloid-leukemia-basic-mechanisms-of-leukemogenesis/vav1-a-key-playerin-agonist-induced-differentiation-of-promyelocytes-from-acute-myeloid-leukemia-ap

\section{INTECH}

open science | open minds

\section{InTech Europe}

University Campus STeP Ri

Slavka Krautzeka 83/A

51000 Rijeka, Croatia

Phone: +385 (51) 770447

Fax: +385 (51) 686166

www.intechopen.com

\section{InTech China}

Unit 405, Office Block, Hotel Equatorial Shanghai

No.65, Yan An Road (West), Shanghai, 200040, China

中国上海市延安西路65号上海国际贵都大饭店办公楼 405 单元

Phone: +86-21-62489820

Fax: $+86-21-62489821$ 
(C) 2011 The Author(s). Licensee IntechOpen. This is an open access article distributed under the terms of the Creative Commons Attribution 3.0 License, which permits unrestricted use, distribution, and reproduction in any medium, provided the original work is properly cited. 